\title{
Volume Fraction
}

National Cancer Institute

\section{Source}

National Cancer Institute. Volume Fraction. NCI Thesaurus. Code C67469.

Quotient of the volume of a component and the total volume of the system containing the component. For clinical chemistry the term component is recommended, ISO uses substance. For clinical chemistry the term system is recommended, ISO uses mixture. 